
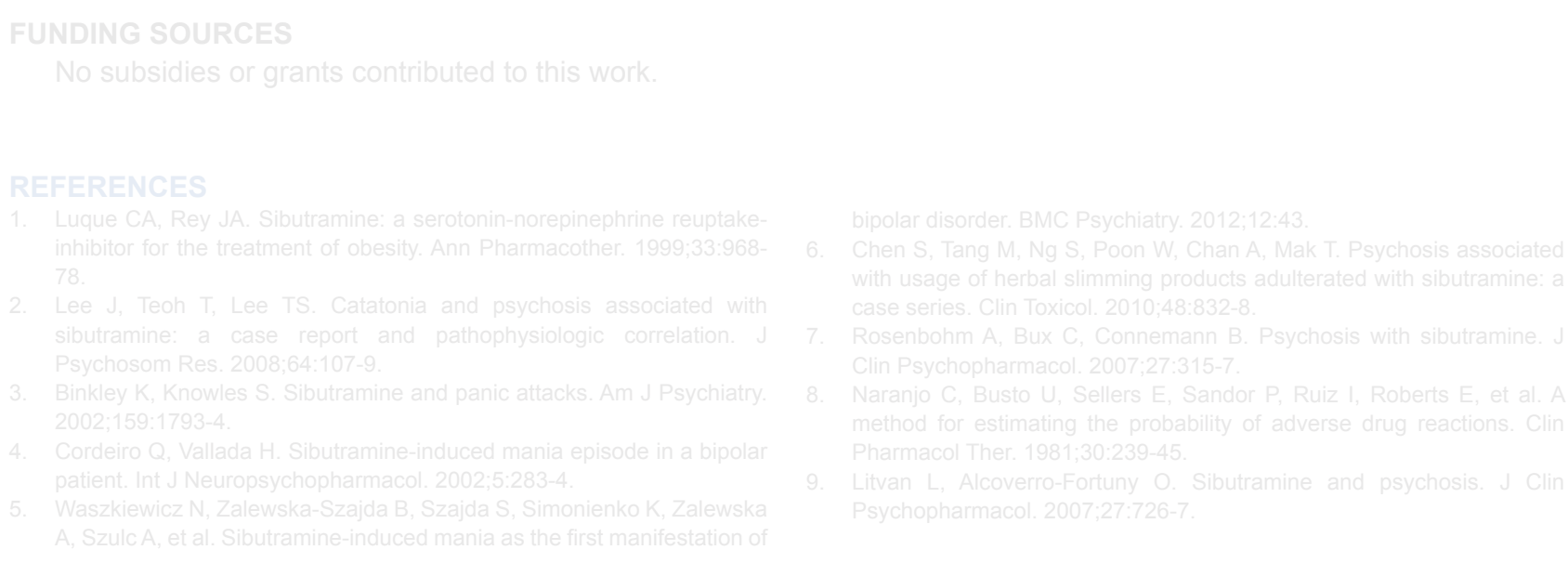

\title{
Granulomas Sarcóides Sobre Cicatriz: Além da Sarcoidose
}

\author{
Sarcoid Granulomas Over Scars: Beyond Sarcoidosis
}

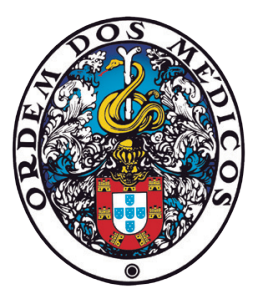

Francisca MORGADO $\rrbracket^{1}$, Mariana BATISTA ${ }^{1}$, José Carlos CARDOSO ${ }^{1}$, Margarida GONÇALO ${ }^{1}$

Acta Med Port 2022 Mar;35(3):218-221 - https://doi.org/10.20344/amp.13451

\section{RESUMO}

Os granulomas sarcóides podem ser encontrados num vasto leque de doenças, pelo que diferenciar a sarcoidose de uma reação tipo sarcóide constituiu um desafio. Apresentamos o caso de uma jovem com lesões papulonodulares eritematovioláceas localizadas nos pavilhões auriculares sobre os locais de aplicação de piercings. A biópsia cutânea mostrou um infiltrado constituído por granulomas sarcóides ou focalmente tuberculóides, não excluindo a hipótese de sarcoidose. O estudo complementar, apesar de uma discreta elevação da enzima conversora da angiotensina, excluiu envolvimento ocular ou pulmonar por sarcoidose. Perante a localização das lesões foram realizados testes epicutâneos que revelaram uma reação fortemente positiva ao paládio e ao níquel, apoiando o diagnóstico de dermatite de contacto granulomatosa. Estão descritos escassos casos de dermatite de contacto granulomatosa ao paládio tendo o metal dos piercings como fonte de sensibilização. A formação de granulomas sarcóides pode representar quer uma reação tipo sarcóide, quer uma forma de sarcoidose cutânea, e os testes epicutâneos adquirem um papel fundamental no diagnóstico correto. Palavras-chave: Cicatriz; Dermatite de Contacto; Granuloma; Paládio; Sarcoidose

\section{ABSTRACT}

Sarcoid granulomas can be found in a wide range of diseases and differentiating sarcoidosis from a sarcoid-like reaction may be a challenge. We present a woman with erythematoviolaceous papulonodular lesions located on the ears where piercings were placed. A skin biopsy showing an infiltrate of sarcoid and focal tuberculoid granulomas did not exclude sarcoidosis. There was a slight increase in the level of angiotensin-converting enzyme. Systemic involvement due to sarcoidosis was excluded. Epicutaneous tests performed revealed a strong positive reaction to palladium and nickel, supporting the diagnosis of granulomatous contact dermatitis. There are only a few reports of granulomatous contact dermatitis to palladium with piercings as the source of sensitization. The formation of sarcoid granulomas can represent either a sarcoid-like reaction or a form of cutaneous sarcoidosis, and patch tests are essential in order to establish the diagnosis.

Keywords: Cicatrix; Contact Dermatitis; Granuloma; Palladium; Sarcoidosis

\section{INTRODUÇÃo}

Os granulomas sarcóides são constituídos por células epitelióides rodeadas por uma escassa coroa linfocitária e sem tendência à caseificação. Podem ser encontrados em lesões de sarcoidose, mas também num vasto leque de outras patologias tais como reações de corpo estranho, sífilis secundária, doença de Crohn, granuloma anular, linfomas e cicatrizes de herpes zoster. Constitui assim um desafio distinguir a sarcoidose de uma reação tipo sarcóide. ${ }^{1,2}$

\section{CASO CLÍNICO}

Doente do sexo feminino, 23 anos, saudável e sem medicação habitual, recorreu à consulta de Dermatologia por lesões cutâneas assintomáticas dos pavilhões auriculares com cerca de 1 ano de evolução. Ao nível dos hélices e lóbulos das orelhas, observavam-se lesões papulonodulares, eritematovioláceas, firmes e de superfície lisa (Fig. 1), com distribuição irregularmente linear nos locais de

\footnotetext{
1. Serviço de Dermatologia. Centro Hospitalar e Universitário de Coimbra. Coimbra. Portugal.

$\square$ Autor correspondente: Francisca Morgado. fjacomemorgado@gmail.com

Recebido: 17 de janeiro de 2020 - Aceite: 24 de julho de 2020 - First published: 06 de dezembro de 2021 - Online issue published: 02 de março de 2022

Copyright $\odot$ Ordem dos Médicos 2022
} 

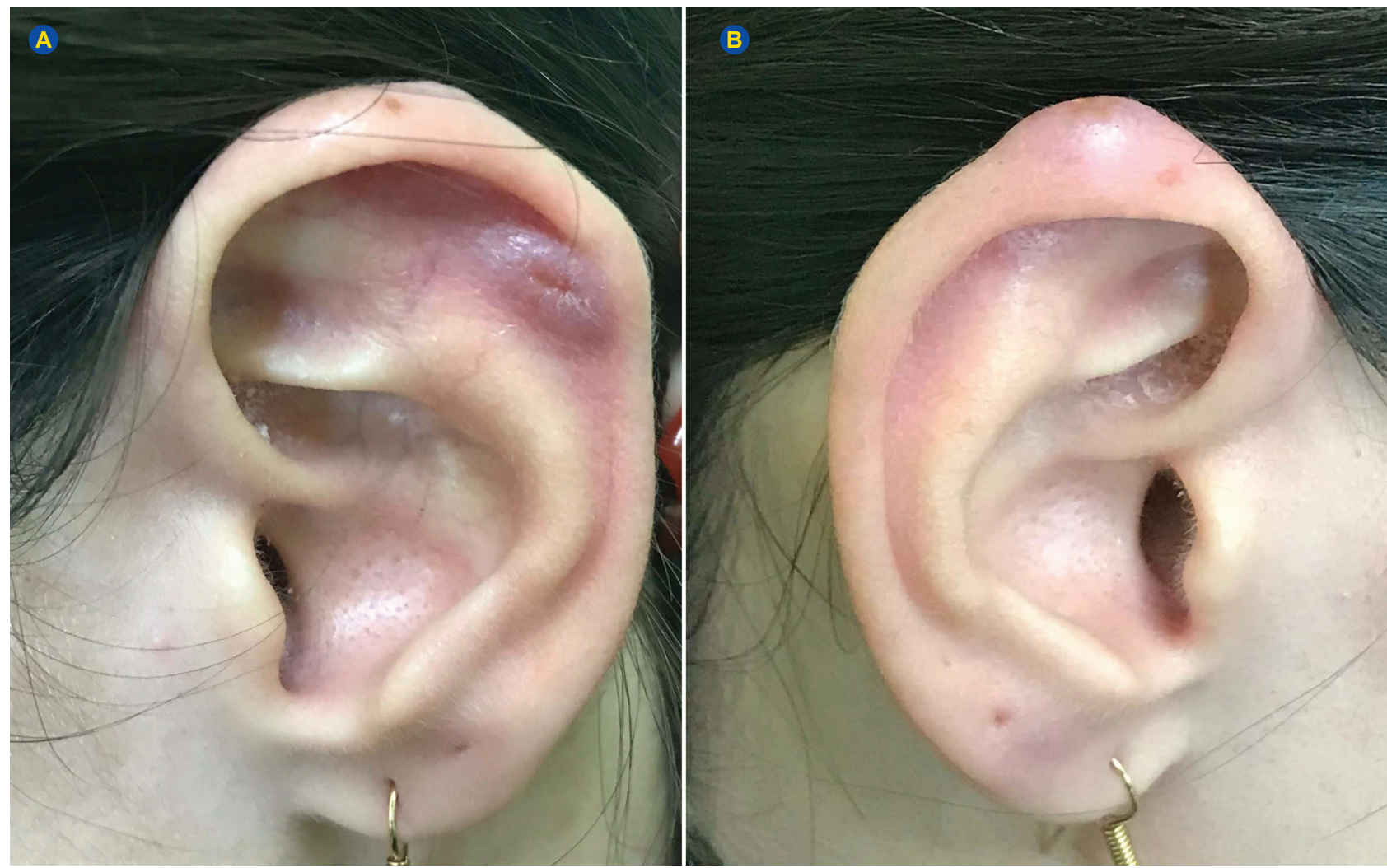

Figura 1 - Lesões cutâneas localizadas sobre os locais de aplicação prévia de piercings; (A) pavilhão auricular esquerdo, (B) pavilhão auricular direito

aplicação de piercings realizados cinco anos antes (sem prurido ou qualquer reação local nessa data). Ao exame objetivo, além das lesões descritas, não foram encontradas outras alterações mucocutâneas ou de órgãos internos.

A biópsia cutânea de uma lesão do pavilhão auricular mostrou um infiltrado granulomatoso envolvendo a derme superficial e profunda, constituído por granulomas sarcóides ou focalmente tuberculóides, não excluindo a hipótese de sarcoidose (Fig. 2).

As análises laboratoriais mostraram apenas uma discreta elevação da enzima conversora da angiotensina (ECA) (60 U/L, N 8 - $52 \mathrm{U} / \mathrm{L})$. A tomografia computorizada de alta resolução não mostrou alterações no parênquima pulmonar nem adenopatias hilares ou mediastínicas, e a observação pela Pneumologia e Oftalmologia excluiu envolvimento destes órgãos.

Perante um diagnóstico empírico de sarcoidose cutânea a doente iniciou corticoterapia tópica (creme de propionato de clobetasol) sem benefício ao fim de seis meses. A vigilância clínica e realização periódica de radiografia do tórax e análises laboratoriais, incluindo novos doseamentos de enzima conversora da angiotensina (ECA) não revelaram alterações. Dois anos após seguimento, perante a localização das lesões e por suspeita
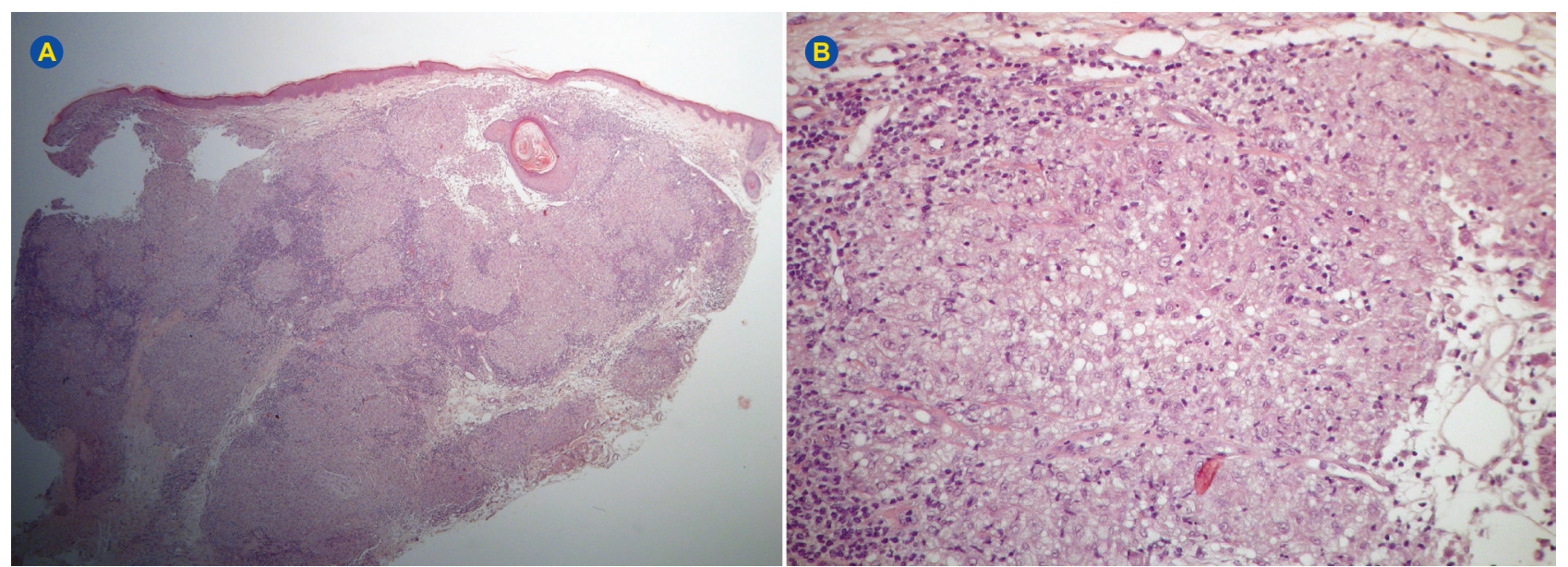

Figura 2 - (A) infiltrado dérmico granulomatoso difuso; (B) granuloma sarcóide: granuloma 'nu', constituído por células epitelióides, sem necrose, com escasso infiltrado linfocitário na periferia. 
de dermatite de contacto com padrão granulomatoso, realizou testes epicutâneos de hipersensibilidade retardada. Os alergénios da série básica europeia e das séries de metais (Chemotechnique diagnostics, Vellinge Sweden ${ }^{\circledR}$ ) foram aplicados no dorso em Finn-Chambers ${ }^{\circledR}$ e mantidos em oclusão durante 48 horas. As leituras realizadas ao fim de três, cinco e sete dias, de acordo com as normas internacionais, revelaram uma reação fortemente positiva (+++) ao paládio (tetracloropaladato de sódio a $3 \%$ vas e cloreto de paládio $2 \%$ vas) e ao níquel (sulfato de níquel $5 \%$ vas), confirmando hipersensibilidade aos metais, nomeadamente ao paládio, frequentemente presente em bijuteria e descrito como causa de dermatite de contacto (DC) granulomatosa.

Perante este diagnóstico, foi suspensa a realização sistemática de exames complementares de diagnóstico para pesquisa de envolvimento sistémico por sarcoidose e, dada a benignidade da dermatose e por opção do paciente, não foram tentados outros tratamentos, nomeadamente corticosteroides intralesionais ou excisão cirúrgica.

\section{DISCUSSÃO}

A sarcoidose cutânea tem um variado espectro de apresentações clínicas e, em cerca de $20 \%$ - 30\% dos casos, o envolvimento cutâneo precede o envolvimento sistémico. ${ }^{3}$ Apesar do exame anatomopatológico apresentar um papel fundamental no diagnóstico, há que ter presente que uma reação granulomatosa não caseosa com granulomas sarcóides não é específico desta doença. Perante este resultado em exames anatomopatológicos de locais de piercings, deve ser considerada a possibilidade de uma reação alérgica.

ADC alérgica, uma reação de hipersensibilidade do tipo IV, cursa habitualmente com eczema, mas pode ter outros padrões clínicos, como reações pustulosas, pigmentares, liquenóides, linfomatóides, tipo de eritema multiforme e, como no presente caso, com formação de granulomas, tipicamente sarcóides - DC granulomatosa.

Múltiplos metais podem estar implicados na génese de granulomas de hipersensibilidade, nomeadamente berílio, alumínio, zircónio, titânio, níquel, mercúrio, crómio, cobalto, paládio e ouro. Os dois últimos são os mais frequentemente envolvidos em lesões cutâneas sobretudo em relação com piercings, uma causa emergente e crescente de DC granulomatosa..$^{4,5}$

A sensibilização ao paládio é quase tão frequente como a sensibilização ao níquel, sendo comum a reação cruzada entre os dois alergénios, mas a reação cutânea é habitualmente de eczema. ${ }^{6} \mathrm{~A}$ formação de granulomas de contacto alérgico tipo sarcoide é rara e foi descrita pela primeira vez em 1983, estando relatados escassos casos de DC granulomatosa ao paládio relacionada com piercings. Ao contrá- rio do eczema, nesta forma de DC as lesões localizam-se de forma exclusiva e desde o início apenas na derme, sem evidência de espongiose e exocitose de linfócitos, típicos das reações de hipersensibilidade de contacto. É possível que a libertação do metal do brinco para a derme possa ocasionar uma reação granulomatosa sem envolvimento da epiderme. Contudo, no teste epicutâneo o paládio induz uma reação eczematosa que, nalguns casos, evolui para um granuloma démico semelhante à reação observada no local de aplicação do piercing, o que não se verificou no caso presente. ${ }^{7}$

As lesões da DC granulomatosa ao paládio relacionados com piercings são habitualmente resistentes à corticoterapia tópica e intralesional obrigando por vezes à excisão cirúrgica. $^{8}$

O presente caso clínico pretende demonstrar que a ocorrência de granulomas sarcóides em biópsias cutâneas pode, em casos raros, dever-se a uma reação de hipersensibilidade. Uma história clínica detalhada e a realização de testes epicutâneos com diferentes metais é necessária para revelar a verdadeira natureza destas lesões.

\section{CONTRIBUTO DOS AUTORES}

FM; MB: Follow-up do doente, redação do manuscrito. JCC: Revisão crítica da descrição e discussão histológica.

MG: Revisão crítica do manuscrito.

\section{PROTEÇÃO DE PESSOAS E ANIMAIS}

Os autores declaram que os procedimentos seguidos estavam de acordo com os regulamentos estabelecidos pelos responsáveis da Comissão de Investigação Clínica e Ética e de acordo com a Declaração de Helsínquia da Associação Médica Mundial actualizada em 2013.

\section{CONFIDENCIALIDADE DOS DADOS}

Os autores declaram ter seguido os protocolos do seu centro de trabalho acerca da publicação de dados.

\section{CONSENTIMENTO DO DOENTE}

Obtido.

\section{CONFLITOS DE INTERESSE}

Os autores declaram não ter conflitos de interesses relacionados com o presente trabalho.

\section{FONTES DE FINANCIAMENTO}

Este trabalho não recebeu qualquer tipo de suporte financeiro de nenhuma entidade no domínio público ou privado.

\section{REFERÊNCIAS}

1. Tchernev G, Tana C, Schiavone C, Cardoso JC, Ananiev J, Wollina U. Sarcoidosis vs. sarcoid-like reactions: the two sides of the same coin?. Wien Med Wochenschr. 2014;164:247-59.

2. Mann RJ, Peachey RD. Sarcoidal tissue reaction--another complication of ear piercing. Clin Exp Dermatol. 1983;8:199-200.
3. Tchernev G, Patterson JW, Nenoff P, Horn LC. Sarcoidosis of the skin-a dermatological puzzle: important differential diagnostic aspects and guidelines for clinical and histopathological recognition. J Eur Acad Dermatol Venereol. 2010;24:125-37.

4. González-Pérez R, Ruiz-Carrillo G, Soloeta R. Sarcoid-type allergic 
contact granuloma caused by earrings in a boy. Actas Dermosifiliogr. 2012;103:73-4.

5. Casper C, Groth W, Hunzelmann N. Sarcoidal-type allergic contact granuloma: a rare complication of ear piercing. Am J Dermatopathol. 2004;26:59-62.

6. Muris J, Goossens A, Gonçalo M, Bircher AJ, Giménez-Arnau A, Foti $C$, et al. Sensitization to palladium in Europe. Contact Dermatitis.
2015;72:11-9.

7. Cardoso R, Reis JP, Gonçalo M, Coelho S, Figueiredo A. Dermatite de contacto granulomatosa ao paládio. Trab Soc Port Derm. 2005:63:4:608

8. Goossens A, De Swerdt A, De Coninck K, Snauwaert JE, Dedeurwaerder $\mathrm{M}$, De Bonte M. Allergic contact granuloma due to palladium following ear piercing. Contact Dermatitis. 2006;55:338-41. 